\title{
Research Paper: Character Reference Choice in the Narratives by Persian-speaking Children With Autism Spectrum Disorder
}

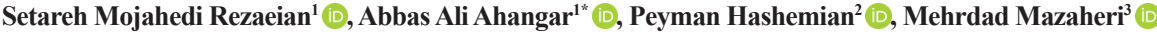

1. Department of English Language and Literature, Faculty of Literature and Humanities, University of Sistan and Baluchestan, Zahedan, Iran.

2. Medical Genetics Research Centre, Mashhad University of Medical Sciences, Mashhad, Iran.

3. Department of Psychology, Faculty of Education and Psychology, University of Sistan and Baluchestan, Zahedan, Iran.

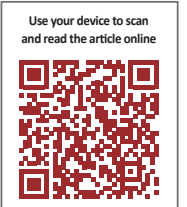

Citation: Mojahedi Rezaeian S, Ahangar AA, Hashemian P, Mazaheri M. Character Reference Choice in the Narratives by Persian-speaking Children With Autism Spectrum Disorder. Journal of Modern Rehabilitation. 2018; 12(1):45-60. http://dx.doi. org/10.32598/jmr.12.1.45

http://dx.doi.org/10.32598/jmr.12.1.45

Funding: See Page 54

(c) Copyright: The Author(s)

Article info:

Received: 15 Jun 2017

Accepted: 05 Oct 2017

Available Online: 01 Jan 2018

\section{Keywords:}

Narrative, Reference introduction, Reference reintroduction, Reference maintenance, Persian-speaking children, Autism

\begin{abstract}
Introduction: The representation of the character reference in different statuses in the narrative is a multifaceted and complicated discourse task. Since Autism Spectrum Disorder (ASD) is interrelated with social and communication deficits; particularly, children with ASD face more challenges with this task. The present study aimed to examine the introduction, reintroduction, and maintenance of the characters reference by using different linguistic devices in the narratives produced by Persian-speaking children with High-Functioning Autism (HFA).
\end{abstract}

Materials and Methods: The narratives were elicited based on the picture story book "Frog, where are you?" Two groups of Persian-speaking children, aged 7,9 and 11 years old, including high-functioning ASD (mean age: 9;5 y; mon) and a control group of Typically Developing (TD) ones (mean age: 9;1 y; mon), each group consisted of 24 subjects participated in this study. Then, the obtained data were analyzed by the Independent sample T Test and Nonparametric Mann-Whitney Test.

Results: The results demonstrated the children with ASD represented referential expressions significantly different from their peer group with regard to using some linguistic devices, in the reference introduction, reintroduction and maintenance $(\mathrm{P}<0.05)$. In particular, the use of noun phrases was dominant for introducing the narrative characters in the two groups under study. However, complete ellipsis was significantly used more by ASD subjects for introducing "the boy" character. In addition, TD children used noun phrases, independent pronouns, dependent pronouns and complete ellipsis for the reintroduction of the referents in their narratives more than autistic children. Finally, for the maintenance of "the boy" reference, whereas autistic children used more noun phrases, TD children frequently used complete ellipsis and inflection of verbs.

Conclusion: The choice of appropriate referential expressions for introduction, reintroduction and maintenance of the reference requires cognitive and linguistic skills, in which children with ASD showed deficits. Among these, reference reintroduction revealed the most challenging function for the children with ASD rather than TD children.

\section{* Corresponding Author:}

Abbas Ali Ahangar, PhD

Address: Department of English Language and Literature, Faculty of Literature and Humanities, University of Sistan and Baluchestan, Zahedan, Iran. Tel: +98 (915) 3412856

E-mail: ahangar@english.usb.ac.ir 


\section{Introduction}

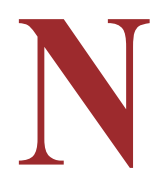

arrative discourse is a pervasive component of verbal communication in many aspects of social and academic life. Narrative, as a spoken or written description of connected discourse events [1-3], is considered a multidimensional skill and developmental trend [4-5] which reflects a variety of linguistic and cognitive knowledge in recollecting experiences [6]. Therefore, in producing narratives to convey a massage, speakers create a context for their addressee(s) via language [7-9] and apply intricate linguistic skills to narrate well-formed narratives [10-11].

It implies that speakers need to be skilled to produce their narratives with adequate clarity at the level of microstructure to represent linguistic features such as sentence structure, reference and semantic information and also at the level of macrostructure to represent global coherence of narrative elements relationship such as story grammar [12-15]. The text is coherent when the addressee can construct a whole mental representation by its different components. In this respect, two reasons can be proposed for the requirement of knowing how participants are referred to in the course of a discourse: addressees want to recognize "who is doing what to whom" and narrators should plainly transfer the same kind of information to the interlocutors in a narrative discourse [16].

In reporting a narrative, the narrators are equipped with various linguistic devices, based on the language specific characteristics, to refer to the characters of an event. Givón [17] proposed a scale for reference representation in which the most coding material was illustrated by full noun phrases, stressed/independent pronouns and unstressed/bound pronouns ('agreement') and the least coding material by zero anaphora. The foundation of this scale emerges from this principle: "The more disruptive, surprising, discontinuous or hard to process a topic is, the more coding material must be assigned to it" [17]. This, in turn, is based on this psychological principle: "Expend only as much energy on a task as is required for its performance" [17].
Similarly, Levinsohn [2] holds that linguistic devices of reference ranges from "complete ellipsis to an implicit reference conveyed only by the inflection of the verb, to two or more sets of independent pronouns (personal and demonstrative, among others), to a full noun phrase (with or without a determiner)". Consequently, regarding different contextual situations, one of the most frequent discursive decisions that speakers make is the choice between referring expressions, namely, they need to select very explicit referring expressions, such as noun phrases or proper nouns, or less explicit ones like pronouns or zeros [18, 19].

For instance, since Persian with its default word order of subject-object-verb, is a pro-drop language, the inflection of the verb mirrors the subject in the case of complete ellipsis (the zero subjects) [20]. This characteristic has an extensive effect on the choice of different linguistic devices to encode the reference based on their status in a narrative. Likewise, in the field of participant reference, Roberts, Barjasteh Delforooz and Jahani [21] provided a scale for referring expressions in Persian language, as shown in Table 1. This illustrates that referring expressions, which belong to a closed system, express information by their forms with their contrastive force. Accordingly, referring expressions, as a whole, can provide information about the "familiarity status of the referent", and also indicate "continuity or change of direction in a discourse" [22].

Since reference to animate or inanimate characters is very dominant and omnipresent element in any narrative, it is one of the most important discourse features that children need to be mastered on $[6,18,23]$. Actually, characters can be in the following statuses in a narrative: they are introduced as new participants for the first time; hey are reintroduced after intervening with the other character(s) during the course of the narrative; and they are maintained as known established characters without any intervention of the other character(s) [23-25].

For instance, when the referent has been mentioned and introduced in the narrative or it is in the focus of attention of the addressee or in an unambiguous condition, narrators tend to use underspecified expressions, such as pronouns or zero [26-30]. Conversely, when the refer-

Table 1. Scale of coding weight for referential expressions in Persian

\section{Persian Referential Expressions}


ent is introduced for the first time or another character is present in the discourse, the narrators more likely to use explicit expressions such as noun phrases or proper nouns to avoid ambiguity $[19,27,31]$. On the other hand, maintenance of character reference in the narratives is generally represented by pronouns or zero [32, 33] which can transfer sufficient information in such a status. Accordingly, it is claimed that the representation of the characters, based on introduction, reintroduction and maintenance, in the narratives via different linguistic devices depends on the status of speaker's mentalizing, attention to the addressee's knowledge and working memory $[18,34]$.

Even though extensive ranges of research on children's referential skills in the various types of discourse and different languages indicate some universal patterns, cross-linguistic differences can be found in the representation of their referential system for character introduction, reintroduction and maintenance in different languages and typically developing children's age groups $[23,24,32,33]$. Autism Spectrum Disorder (ASD), as a neurodevelopmental disorder, signifies a scale of mild to severe impairments in mutual social interaction, repetitive behaviors, and constrained interests. It is characterized by insistent deficits in nonverbal and verbal communicative behaviors $[35,36]$.

Despite some similarities in language abilities [25, 37, 38], various studies reported a wide variety of linguistic differences and impairments for children with ASD [3941], particularly in the discursive and pragmatic aspects, in which various kinds of rules and processes govern the contextual suitability of language [42-46]. Some literature on referential choices made by children with ASD proposed that, due to impairments in attention, working memory, mental processes and difficulties in using pronouns, they tended to adhere their narratives to the explicit referential expressions such as full lexical noun phrases [18, 47]. However, in some studies it was observed that children with ASD used pronouns and zeros too much in their narratives, for example when the referent was in their own focus of attention but not in their interlocutors' attention [44].

In sum, although various verbal characteristics and deficits of children with ASD have been widely investigated in different research studies, little is known about their abilities and impairments in choosing appropriate referential expressions for the representation of the characters in different discourse contexts. This gap is obviously apparent in introducing, reintroducing, and maintaining referents in the narratives, especially in Per- sian-speaking children with ASD. As reported in different studies, given the intricate linguistic skills required for producing narratives, children with different kinds of disorders such as ASD as well as learning and cognitive disabilities may have some difficulties in producing narratives [48, 49]. Even though different dimensions of narratives have been extensively examined, the range of studies about the narrative abilities of children with ASD show contradictory claims.

Actually, the development of narrative skills, particularly reference representations without making ambiguities, interrelates with social and academic life of the speakers. Thus, the study of reference representation characteristics in producing and understanding the narratives by children with ASD and comparing with Typically Developing (TD) peer group can be perceived as an informative predictor in this special aspect of narrative for necessary future intervention in their educational programs.

In light of what was mentioned, this study aimed to survey the referring expressions, including noun phrases, independent pronouns, dependent pronouns, complete ellipsis, and inflection of verb, by which high-functioning Persian-speaking children with autism represent the reference introduction, reintroduction and maintenance in their narratives. To this end, this study aims to answer the following research questions: 1 . Does the character reference introduction significantly differ in terms of using referring expressions in Persian-speaking high-functioning children with ASD compared to TD children's narratives?; 2. Does the character reference reintroduction significantly differ in terms of using referring expressions in Persian-speaking high-functioning children with ASD compared to TD children's narratives?; and 3. Does the character reference maintenance significantly differ in terms of using referring expressions in Persianspeaking high-functioning children with ASD compared to TD children's narratives?

Accordingly, the hypotheses of the research are as the following: 1. The character reference introduction does significantly differ in terms of using referring expressions in Persian-speaking high-functioning children with ASD compared to TD children's narratives; 2 . The character reference reintroduction does significantly differ in terms of using referring expressions in Persianspeaking high-functioning children with ASD compared to TD children's narratives; and 3 . The character reference maintenance does significantly differ in terms of using referring expressions in Persian-speaking highfunctioning children with ASD compared to TD children's narratives. 


\section{Materials and Methods}

\section{Participants}

Forty-eight Persian-speaking boys from age groups of 7, 9 and 11 years, each age group consisted of 8 subjects, participated in this study. All the subjects were monolingual Persian-speaking elementary school children with middle socioeconomic status from Mashhad City, Iran. Twenty-four subjects were children with high-functioning autism (Mean [SD] age: 9;17[1;69] $\mathrm{y}$; mon) from an exceptional school, Noore Hedayat School, and 24 of them, the matched-age group of TD children (Mean [SD] age: 9;57[1;67] y; mon) from an ordinary school, Hojjat School.

High-functioning autism group subjects were chosen from the children who were initially diagnosed by a child psychiatrist. Afterwards, Gilliam Autism Rating Scale-2 (GARS-2) [50] were completed by children's parents. The Gilliam Autism Rating Scale (GARS-2) is a measure and screening tool for ASD in individuals aged between 3 and 22 years. It can be completed by parents and teachers in different settings, such as home and school. They are required to select from one of the four possible choices provided for each of 42 Likert-type items, ranging from 0 (never observed) to 3 (frequently observed). GARS-2 is available in Persian whose psychometric properties have been assessed for identifying
Persian-speaking children with autism by Ahmadi, Safari, Hemmatian and Khalili, [51, 52].

It is divided into three key subscales: stereotyped behaviors, communication, and social interaction which can differentiate people with autism from other disorders. In addition, the age variable has no effect on GARS-2 scores. Then, the Autism Spectrum Screening Questionnaire (ASSQ) [53] was completed by parents or teachers of children with ASD. This questionnaire is filled out by the parents (higher than 19 scores= highfunctioning autism) or teachers (higher than 22 scores= high-functioning Autism) of children or adolescents aged between 6 to 17 years.

It consists of 27 items and stands for screening ASDs. Each question had three possible answers; no, somewhat, and yes, and each question has a score from 0 to 2 . The inclusion criteria for High-Functioning Autism (HFA) subjects were receiving scores between 69-79 in their GARS-2 forms, higher than 19 in their ASSQ forms, being normal or higher than normal IQ scores in Wechsler Intelligence Scale for Children-Revised (WISC-R) [54], and the production of at least 50 or more utterances by each subject to determine the Mean Length of Utterance (MLU), as shown in Table 2.

It is claimed that, generally, 50 to 100 utterances are regarded a sufficient narrative sample for analyzing a

Table 2. Demographic and diagnostic information for HFA and TD Persian-speaking children

\begin{tabular}{|c|c|c|}
\hline \multirow{2}{*}{ Variables } & \multicolumn{2}{|c|}{ Mean (SD) } \\
\hline & HFA (n=24 Male) & TD (n=24 Male) \\
\hline Age (year; month) & $9 ; 5(1 ; 6)$ & $9 ; 1(1 ; 6)$ \\
\hline MLU & $2.86(0.68)$ & $4.19(0.89)$ \\
\hline $\mathrm{IQ}$ & $108.58(7.84)$ & $124.12(5.29)$ \\
\hline Verbal & $97.83(6.59)$ & $117.58(6.74)$ \\
\hline Performance & 117.25(10.99) & $126.16(4.55)$ \\
\hline GARS-2 & $73.66(2.95)$ & \\
\hline Stereotyped behaviors & $21.29(1.87)$ & \\
\hline Communication & $20.37(1.01)$ & \\
\hline Social interaction & $21.70(1.45)$ & \\
\hline ASSQ & $23.79(3.72)$ & \\
\hline
\end{tabular}


speaker's overall production. An utterance may be a sentence or a shorter unit. To determine the speaker's MLU, after counting morphemes for each utterance, they are totaled and then divided by the total number of utterances. Normally, higher MLU up to 4.0, corresponds to increase in utterance complexity [55]. Furthermore, any hearing, mental or neurological dysfunctions, and any other psychiatric disorders were not reported in the subjects' profiles.

\section{Study procedure}

All children were individually tested in a quiet room in their school, in two different sessions. In the first phase, their IQ were tested by Persian adapted and standardized version of Wechsler Intelligence Scale for ChildrenRevised (WISC-R) [54]. In the second phase, they were asked to participate in a 'story-telling game', in which they had to tell a story for one of the researchers who was not simultaneously able to see the picture book, "Frog, where are you?" [56].

In this situation, the narrators need to apply the most appropriate referential expressions based on their interlocutor's focus of attention. As to the story, it is about a boy who has a dog and a frog. After the frog escapes, the boy and his dog tried to find the frog. During their search, they encountered different animals and challenging events in the jungle. The outcome of this search was to find the frog with a family near the pond. As the elicitation tool, in many different languages, this story has extensively been applied to study narratives made by TD children $[57,58]$ or children with some language impairments [25, 59-61]. In addition, because of the causal relationship between events, appearance and disappearance of the story characters in different situations [57], this pictorial story can be an appropriate eliciting tool to make the subjects recall their both linguistic and cognitive knowledge for representing character introduction, reintroduction, and maintenance via different linguistic devices. Therefore, the task of telling a narrative was, at first, explained by one of the researchers to all the children individually.

The children were allowed to turn the pages of the book. Then, it was explained that this is a picture book and he/she should narrate a story based on the pictures. During data eliciting, the researcher intervened as little as possible, simply expressed some phatic expressions or sentences such as "uh huh" and "Well, that's right", asked general questions e.g. "Then, what happened?" or repeated the last produced sentence to motivate the child to continue. The produced narratives were recorded by a voice recorder. Generally, producing one narrative took about 20-30 minutes for high-functioning children with autism, because of their somehow slow speaking, and 10-15 minutes for typically developing children.

\section{Data transcription and coding}

All the produced and recorded narratives were exactly transcribed word by word, and then, unnecessary utterances such as questions asked by the children to receive information (e.g. 'Is this a deer?') were excluded from the analysis. In line with the extensive literature on the narrative analysis, the unit of narrative discourse analysis in this study was considered as T-unit which was one independent clause and any dependent clauses [13, 62-64].

Then, each character reference, represented by one of the linguistic devices of noun phrases, dependent pronouns, independent pronouns, complete ellipsis and inflection of verb (see Appendix A, for variables definitions and examples) was identified and coded for the narrative statuses, including introduction, reintroduction and maintenance, as in the following examples [1-4] (see Appendix B for more introduction examples, Appendix $\mathrm{C}$ for more reintroduction examples, and Appendix D for more maintenance examples):

(1) $\boldsymbol{\emptyset}^{1}[\text { Intro }]^{2}$ xabid.

$\varnothing \quad$ sleep.PAST.3SG ${ }^{3}$

'Ø (he) slept.'

(2) pesær [Intro] je qurbaqe daft

ba je sæg.
boy one frog have.PAST.3SG
with one dog

'The boy had a frog with a dog.'

(3) pesær ræft bala-j-e deræxt, bæ:d Ø [Reintro $]^{4}$ oftad.

$\mathrm{EZ}^{6}$ tree, ${ }^{\text {go.PAST.3SG }}$ then $\varnothing$ top- $\mathrm{HI}^{5}$ -

fall.PAST.3SG

1. Zero

2. Introduction

3. Third person singular

4. Reintroduction

5. Hiatus

6. ezafe marker 
'The boy climbed up the tree, then $\boldsymbol{\emptyset}$ (he) fell'.

(4) pesær seda zæd, oftad pajin.

pesær [Maintain] $]^{7}$

boy sound hit.PAST.3SG boy

fall.PAST.3SG down

'The boy called, the boy fell down'.

Subsequently, ten narratives from 48 ones, produced by high-functioning ASD and TD children, were randomly selected and then analyzed by two authors to assess inter-rater reliability. Point-by-point agreement in scoring between raters was $98 \%$ for all the given variables.

\section{Statistical analysis}

To examine the research hypotheses, the mean of using different linguistic devices for the introduction, reintroduction, and maintenance of the character reference in Persian-speaking high-functioning children with autism spectrum disorder's narratives was compared to typically developing children's. Since the sample size was small in the two groups, we examined the normality assumption to select the appropriate test. If the assumption of normality and variance equality of observations was met in the two groups, the independent sample t test was used. However, if the distribution of the observations was not normal in the two groups or one of the groups, nonparametric Mann-Whitney was used for comparing the two groups $(\mathrm{P}<0.05)$.

\section{Results}

Table 3 indicates that using linguistic devices for the introduction of the referents was significantly different only for introducing "the boy" by complete ellipsis in ASD subjects. So, hypothesis (1) is accepted as far as the introduction of "the boy" is concerned $(\mathrm{P}<0.05)$. As to the use of other linguistic devices, this hypothesis is rejected $(\mathrm{P}>0.05)$ (Significant values are in bold in Table 3). Regarding the mean values, more complete ellipsis has been applied in autistic children's narratives than TD children's. In addition, using noun phrases is dominant for the introduction of the three characters, including "the boy", "the dog", and "the frog" in the two groups under study.

In Table 4, the mean values show that in the most cases using different linguistic devices for the reintroduction of the referents is more frequent in the narratives of TD

7. Maintenance children in comparison to the autistic children. However, this difference is significant in some cases. Regarding tests results, except for noun phrases and inflection of verb for "the boy" reintroduction, noun phrases, independent pronouns, complete ellipsis and inflection of verb for "the dog" reintroduction, and independent pronouns and inflection of verb for "the frog" reintroduction, there is a significant difference in using dependent pronouns, independent pronouns and complete ellipsis for the reintroduction of "the boy", dependent pronouns for the reintroduction of "the dog", noun phrases, dependent pronouns and complete ellipsis for the reintroduction of "the frog" between the autistic and typically developing children. Thus, hypothesis 2 is accepted for only using these linguistic devices $(\mathrm{P}<0.05)$, while it is rejected for the rest $(\mathrm{P}>0.05)$. In the other words, TD children use these devices for the reintroduction of the referents in their narratives more than autistic children, as shown bold in Table 4 .

In addition, the mean values demonstrate that in the most cases the use of different linguistic devices for the maintenance of the referents is generally more in the TD children's narratives than autistic ones. Out of these, using two devices indicates a significant difference, including complete ellipsis and inflection of verb for the maintenance of "the boy" reference. Nonetheless, compared to TD children, autistic children used more noun phrases for the maintenance of "the boy" reference, and this is a statistically significant difference. Hence, hypothesis (3) is accepted regarding these linguistic devices $(\mathrm{P}<0.05)$, whereas, it is rejected for others $(\mathrm{P}>0.05)$. In the other words, TD children use more complete ellipsis and inflection of verb for the maintenance of "the boy" reference than autistic children, as given in Table 5.

\section{Discussion}

The present research examined the representation of the character reference in terms of different linguistic devices or expressions for the introduction, reintroduction and maintenance statuses in narratives produced by Persian-speaking high-functioning children with ASD and typically developing ones. The analysis of the elicited data from both groups demonstrated significant differences in some cases of using various linguistic devices for the introduction, reintroduction and maintenance of character reference representation, which can be related to some claimed impairments and distinctive characteristics in the narratives of autistic children. Typically, narrators, regarding their interlocutor's focus of attention, need to make use of the most appropriate referential expressions to represent characters in different narrative 
Table 3. The mean of using different linguistic devices to introduce characters in ASD and TD Persian-speaking children's narratives

\begin{tabular}{|c|c|c|c|c|}
\hline \multirow{2}{*}{ Introduction } & \multirow{2}{*}{ Items } & \multicolumn{2}{|c|}{ Mean (SD) } & \multirow{2}{*}{$\mathbf{P}$} \\
\hline & & ASD $(N=24)$ & TD (N=24) & \\
\hline \multirow{5}{*}{ Boy } & Noun phrase & $0.83(0.38)$ & $0.91(0.28)$ & 0.38 \\
\hline & Dependent pronoun & $0.12(0.44)$ & $0.04(0.20)$ & 0.53 \\
\hline & Independent pronoun & $0.00(0.00)$ & $0.08(0.28)$ & 0.15 \\
\hline & Complete ellipsis & $0.16(0.38)$ & $0.00(0.00)$ & 0.03 \\
\hline & Inflection of verb & $0.87(0.44)$ & $0.91(0.28)$ & 0.66 \\
\hline \multirow{5}{*}{ Dog } & Noun phrase & $0.91(0.28)$ & $1.00(0.00)$ & 0.15 \\
\hline & Dependent pronoun & $0.00\left(0.00^{\mathrm{a}}\right)$ & $0.00\left(0.00^{\mathrm{a}}\right)$ & ---- \\
\hline & Independent pronoun & $0.04(0.20)$ & $0.00(0.00)$ & 0.31 \\
\hline & Complete ellipsis & $0.04(0.20)$ & $0.00(0.00)$ & 0.31 \\
\hline & Inflection of verb & $0.29(0.46)$ & $0.41(0.50)$ & 0.37 \\
\hline \multirow{5}{*}{ Frog } & Noun phrase & $0.87(0.33)$ & $1.00(0.00)$ & 0.07 \\
\hline & Dependent pronoun & $0.04(0.20)$ & $0.00(0.00)$ & 0.31 \\
\hline & Independent pronoun & $0.00\left(0.00^{\mathrm{a}}\right)$ & $0.00\left(0.00^{\mathrm{a}}\right)$ & ----- \\
\hline & Complete ellipsis & $0.08(0.28)$ & $0.00(0.00)$ & 0.15 \\
\hline & Inflection of verb & $0.29(0.46)$ & $0.08(0.28)$ & 0.06 \\
\hline
\end{tabular}

a. Test cannot be done because the standard deviations of both groups are 0 .

statuses. With respect to gathered data based on the character reference representation, the results of this study support some previous research that demonstrate impairments and differences in reference production.

First, the choice of referential form by the subjects was sensitive to the referent status, which is introduction, reintroduction, and maintenance of the referent. However, the frequency of using different referential forms was more in the TD children's narratives. This can be attributed to the fact that overall MLU is fewer in autistic subjects' narratives than TD children's narratives (as shown in Table 2). Thus, as Arnold, Bennetto and Diel [18] found, the autistic participants exhibit an inclination to produce fewer references than TD subjects in their narratives.

Second, the character reference introduction via different referential expressions was very similar in the two groups under study. In the way that reference introduction was dominantly accomplished by noun phrases in the narratives produced by HFA children and TD chil- dren. Actually, regarding mental representation, to introduce a reference for the first time, the most suitable revealing referential expression can be a noun phrase, which is the most coding material [24].

In consistent with evidence provided by some research $[18,47]$, this finding can be explained by these proposed predictions that, in general, children with autism tended to overuse the explicit expressions in their narratives; furthermore, when they wanted to introduce the referent for the first time, they were sensitive to their addressees' focus of attention. This is in contrast with Tager-Flusberg's [44] finding that children with autism were unsuccessful to introduce new characters with noun phrases; since, in her study, children with autism dominantly made use of pronouns and were less likely to introduce new characters in a clear way in comparison to normal children.

Surprisingly, the significant difference was that ASD children used more complete ellipsis device for the introduction of "the boy" character in comparison to TD children; while, this type of character reference introduc- 
Table 4. The mean of using different linguistic devices to reintroduce characters in ASD and TD Persian-speaking children's narratives

\begin{tabular}{|c|c|c|c|c|}
\hline \multirow{2}{*}{ Reintroduction } & \multirow{2}{*}{ Items } & \multicolumn{2}{|c|}{ Mean (SD) } & \multirow{2}{*}{$\mathbf{P}$} \\
\hline & & ASD $(n=24)$ & TD $(n=24)$ & \\
\hline \multirow{5}{*}{ Boy } & Noun phrase & $8.41(5.61)$ & $6.29(4.14)$ & 0.14 \\
\hline & Dependent pronoun & $2.95(4.00)$ & $6.75(3.60)$ & 0.00 \\
\hline & Independent pronoun & $0.91(1.76)$ & $2.45(3.34)$ & 0.01 \\
\hline & Complete ellipsis & $3.08(2.55)$ & $6.79(3.74)$ & 0.00 \\
\hline & Inflection of verb & $10.29(5.61)$ & $13.58(5.88)$ & 0.05 \\
\hline \multirow{5}{*}{ Dog } & Noun phrase & $7.41(5.42)$ & $9.08(5.13)$ & 0.20 \\
\hline & Dependent pronoun & $0.41(0.65)$ & $1.87(2.30)$ & 0.00 \\
\hline & Independent pronoun & $0.33(0.70)$ & $0.50(0.78)$ & 0.36 \\
\hline & Complete ellipsis & $0.25(0.53)$ & $0.37(0.71)$ & 0.64 \\
\hline & Inflection of verb & $4.50(2.90)$ & $5.70(3.78)$ & 0.37 \\
\hline \multirow{5}{*}{ Frog } & Noun phrase & $5.12(3.95)$ & $6.62(2.73)$ & 0.03 \\
\hline & Dependent pronoun & $0.45(0.72)$ & $3.70(3.51)$ & 0.00 \\
\hline & Independent pronoun & $0.29(0.90)$ & $0.45(.83)$ & 0.19 \\
\hline & Complete ellipsis & $0.33(0.86)$ & $1.16(1.04)$ & 0.00 \\
\hline & Inflection of verb & $3.83(2.72)$ & $4.87(2.15)$ & 0.05 \\
\hline
\end{tabular}

JMR

ing was not observed in TD children's narratives. This finding can support the evidence that, because of some deficits in attention, children with ASD are more likely to produce ambiguous references than TD peer groups $[25,38]$. It can also be related to attention, memory and pragmatics deficits, which is partly in line with TagerFlusberg's [44] claim.

Third, character reference reintroduction and maintenance were more challenging than character reference introduction and it made more cognitive and linguistic load for the narrators. Reintroduction of "the boy" and "the dog" characters was different from "the frog," because "the boy" and "the dog" are active references in almost every scene. Thus, other devices than the noun phrase would be sufficient expression for "the boy" and "the dog" reintroduction, but "the frog" needed to be specified by the noun phrase to avoid ambiguity.

In the most cases, there were meaningful differences in using referential expressions in HFA children and TD children's narratives. Accordingly, HFA children made use of dependent pronouns, independent pronouns and complete ellipsis to reintroduce "the boy" reference less than TD children. Instead, they predominantly preferred to use the noun phrase to reintroduce the referent "the boy" in their narratives, which was in line with this claim that, due to some impairments in their memory and attentional processes, children with ASD restrict their referential expressions to the more explicit ones [18].

To reintroduce "the dog" reference, a meaningful difference was observed only in using dependent pronouns between HFA children and TD children groups. The "the dog" character is present in most of the scenes, accompanying "the boy." Using dependent pronouns to reintroduce "the dog" was more in TD children's narratives in comparison with HFA children. This finding once more asserts that children with autism tend to use fewer pronouns, whether independent or dependent ones, in the situations that a less coding material is suitable. In addition, to reintroduce "the frog" reference, which is not present after it escapes in the second scene until the end of the story, while all the searches were done to find it, 
Table 5. The mean of using different linguistic devices to maintain characters in ASD and TD Persian-speaking children's narratives

\begin{tabular}{|c|c|c|c|c|}
\hline \multirow[b]{2}{*}{ Maintenance } & \multirow{2}{*}{ Items } & \multicolumn{2}{|c|}{ Mean (SD) } & \multirow{2}{*}{$\mathbf{P}$} \\
\hline & & $\operatorname{ASD}(n=24)$ & TD $(n=24)$ & \\
\hline \multirow{5}{*}{ Boy } & Noun phrase & $3.29(3.47)$ & $\mathbf{0 . 8 7}(1.15)$ & 0.00 \\
\hline & Dependent pronoun & $0.41(0.71)$ & $0.62(0.96)$ & 0.49 \\
\hline & Independent pronoun & $0.20(0.58)$ & $0.70(1.30)$ & 0.05 \\
\hline & Complete ellipsis & $2.37(2.42)$ & $6.79(4.50)$ & 0.00 \\
\hline & Inflection of verb & $5.83(2.76)$ & $8.04(3.96)$ & 0.03 \\
\hline \multirow{5}{*}{ Dog } & Noun phrase & $0.25(0.53)$ & $0.25(0.60)$ & 0.78 \\
\hline & Dependent pronoun & $0.08(0.28)$ & $0.16(0.38)$ & 0.38 \\
\hline & Independent pronoun & $0.04(0.20)$ & $0.04(0.20)$ & 1.00 \\
\hline & Complete ellipsis & $0.25(0.60)$ & $0.41(0.65)$ & 0.23 \\
\hline & Inflection of verb & $0.54(0.93)$ & $0.62(0.96)$ & 0.74 \\
\hline \multirow{5}{*}{ Frog } & Noun phrase & $0.20(0.50)$ & $0.29(0.62)$ & 0.68 \\
\hline & Dependent pronoun & $0.04(0.20)$ & $0.20(0.58)$ & 0.28 \\
\hline & Independent pronoun & $0.00\left(0.00^{\mathrm{a}}\right)$ & $0.00\left(0.00^{\mathrm{a}}\right)$ & ----- \\
\hline & Complete ellipsis & $0.29(0.69)$ & $0.75(1.11)$ & 0.09 \\
\hline & Inflection of verb & $0.45(0.88)$ & $1.00(1.38)$ & 0.10 \\
\hline
\end{tabular}

a. Test cannot be done because the standard deviations of both groups are 0 .

there was a meaningful difference in using noun phrases, dependent pronouns and complete ellipsis between HFA children and TD children. That is, TD children in comparison with HFA children used more noun phrases to reintroduce "the frog" in their narratives. Nonetheless, the dominant referential expression was the noun phrase in the narratives of children with ASD, this finding indicated that children with ASD could effectively reintroduce the reference in their narratives $[18,47]$.

Similarly, the results indicate a meaningful difference in using noun phrases, complete ellipsis and inflection of verb only for the maintenance of the "the boy" reference; unlikely, the findings reveal no significant difference in the maintenance of "the dog" and "the frog" referents in terms of applying referential expressions between TD and ASD children's narratives. Interestingly, for maintaining "the boy" reference HFA children preferred to use more noun phrases than TD children in their narratives. In this status, the result support the memory deficits in children with ASD $[65,66]$ and also Arnold, Bennetto and Diehl's [18] statement that "they have a higher threshold for deciding that a pronoun or zero is sufficient". In the other words, TD children prefer to apply less coding material such as complete ellipsis and inflection of verb in the situations which would not lead to ambiguity.

Finally, it should be noted that one of the most prominent limitations of the current study was the lack or poor cooperation of children with autism in narrative task, which can be attributed to their clinical characteristics. Actually, this limitation considerably affected the sample size of the study. So, the researcher had to patiently spend more time to communicate with autistic child for eliciting the narrative. Besides, to determine the fact that whether these findings are specific to autism spectrum disorder, children with other developmental and cognitive disorders need to be investigated in the future studies, in a larger sample size and in various age groups.

Because narrative discourse is an indispensable cognitive and linguistic aspect of social life, it can highly influence the communicative skills. This study investigated the referential expression choice for the representation of the intro- 
duction, reintroduction, and maintenance of the characters reference in narratives by Persian-speaking children with HFA. The mean values of the representations demonstrated that there were significantly some differences between children with ASD and TD children's references in the narratives under investigation. Introducing, reintroducing and maintaining the character reference by various referential expressions in autistic subjects was affected by some impairments in considering their addressees' focus of attention and memory. Reintroducing a referent revealed the most degree of difference in the two groups.

That is, children with ASD had a tendency to rely on the devices with more coding materials. On the whole, these differences support the interrelated effect of cognitive load on the referential choice, which can be explained as a preference of overspecification $[18,27]$. It implies that specialists in the field of children with ASD need to provide situations in which these children can distinguish the sufficient materials for the representations of the character references in a narrative, regarding their attention and memory deficits. Consequently, children with ASD who have different threshold from TD children and require some intervention programs, for example, to be able to use pronouns or complete ellipsis in the appropriate contexts more efficiently.

\section{Ethical Considerations}

\section{Compliance with ethical guidelines}

To conduct narrative eliciting test, formal permission was first taken from Mashhad Education and Training Office. Then, children's parents and teachers signed the consent form.

\section{Funding}

The authors received no financial support for the research, authorship, and/or publication of this article.

\section{Conflict of interest}

The authors declared no potential conflicts of interest with respect to the research, authorship, and/or publication of this article.

\section{Acknowledgments}

The authors gratefully acknowledge Mashhad Education and Training Office, District 7, the staff and teachers of Hojjat Elementary School, and Noore Hedayat Exceptional School and especially all the children who participated in the study, and their parents cooperated kindly.

\section{References}

[1] Boudreau DM. Narrative abilities in children with language impairments. In: Paul R, editor. Language Disorders From a Developmental Perspective. Mahwah, NJ: Lawrence Erlbaum Associates; 2007. [PMID]

[2] Levinsohn SH. Self-instruction materials on narrative discourse analysis. Dallas: SIL International; 2015.

[3] Rumelhart, DE. Notes on a schema for stories. In: Bobrow DG, Collins A, editors. Representation and Understanding: Studies in Cognitive Science. New York: Academic Press; 1975. [DOI:10.1016/B978-0-12-108550-6.50013-6]

[4] Mäkinen L, Loukusa S, Nieminen L, Leinonen E, Kunnari $S$. The development of narrative productivity, syntactic complexity, referential cohesion and event content in fourto eight-year-old Finnish children. First Language. 2013; 34(1):24-42. [DOI:10.1177/0142723713511000]

[5] Westerveld, MF, Moran CA. Spoken expository discourse of children and adolescents: Retelling versus generation. Clinical Linguistics \& Phonetics. 2013; 27:720-34. [DOI:10.3109/02 699206.2013.802016] [PMID]

[6] Kibrik AA. Reference in discourse. Oxford: Oxford University Press; 2011. [DOI:10.1093/acprof:oso/9780199215805.001.0001] [PMID]

[7] Krauss, RM, Chiu, CY. Language and social behavior. In: Gilbert DT, Fiske ST, Lindzey G, editors. The handbook of social psychology. New York: McGraw-Hill; 1998. [PMID]

[8] Ravid D, Tolchinsky L. Developing linguistic literacy: A comprehensive model. Journal of Child Language. 2002; 29(2):417-47. [DOI:10.1017/S0305000902005111] [PMID]

[9] Snow CE. The theoretical basis for relationships between language and literacy in development. Journal of Research in Childhood Education. 1991; 6(1):5-10. [DOI:10.1080/02568549109594817]

[10] Karmiloff-Smith A. Beyond modularity: A developmental perspective on cognitive science. Cambridge: MIT Press; 1995.

[11] Petersen DB. A systematic review of narrative-based language intervention with children who have language impairment. Communication Disorders Quarterly. 2010; 32(4):20720. [DOI:10.1177/1525740109353937]

[12] Carroll DW. Psychology of language. Belmont: Thomson Wadsworth; 2008.

[13] Justice LM, Bowles R, Pence K, Gosse C. A scalable tool for assessing children's language abilities within a narrative context: The NAP (Narrative Assessment Protocol). Early Childhood Research Quarterly. 2010; 25(2):218-34. [DOI:10.1016/j. ecresq.2009.11.002]

[14] Liles BZ. Production and comprehension of narrative discourse in normal and language disordered children. Journal of Communication Disorders. 1985; 18(6):409-27. [DOI:10.1016/0021-9924(85)90030-9]

[15] Pinto G, Tarchi C, Bigozzi L. Development in narrative competences from oral to written stories in five-to sevenyear-old children. Early Childhood Research Quarterly. 2016; 36:1-10. [DOI:10.1016/j.ecresq.2015.12.001] 
[16] Dooley RA, Levinsohn SH. Analyzing discourse: A manual of basic concepts. Dallas: SIL International; 2000.

[17] Givon T. Topic continuity in discourse: A quantitative cross-language study. Amsterdam: John Benjamins Publishing Company; 1983.

[18] Arnold JE, Bennetto L, Diehl JJ. Reference production in young speakers with and without autism: Effects of discourse status and processing constraints. Cognition. 2009; 110(2):131-46. [DOI:10.1016/j.cognition.2008.10.016] [PMID] [PMCID]

[19] Gundel JK, Hedberg N, Zacharski R. Cognitive status and the form of referring expressions. JSTOR. 1993; 69(2):274-307. [DOI:10.2307/416535]

[20] Dabir-Moqaddam, M. [Theoretical linguistics: Emergence and development of the generative grammar (Persian)]. Tehran: SAMT; 2010.

[21] Roberts JR, Barjasteh Delforooz B, Jahani C. A study of Persian discourse structure. Amsterdam: Acta Universitatis Upsaliensis; 2009

[22] Smith CS. Modes of discourse: The local structure of texts (Vol. 103). Cambridge: Cambridge University Press; 2003.

[23] Hickmann, M. Children's discourse: Person, space and time across languages. Cambridge: Cambridge University Press; 2004.

[24] Aksu-Koç A, Nicolopoulou A. Character reference in young children's narratives: A crosslinguistic comparison of English, Greek, and Turkish. Lingua. 2015; 155:62-84. [DOI:10.1016/j.lingua.2014.04.006]

[25] Norbury CF, Bishop DVM. Narrative skills of children with communication impairments. International Journal of Language \& Communication Disorders. 2003; 38(3):287-313. [DOI:10.1080/136820310000108133] [PMID]

[26] Ariel, M. Accessing noun-phrase antecedents (rle linguistics b: Grammar). London: Routledge; 2014 [DOI:10.4324/9781315857473]

[27] Arnold JE, Griffin ZM. The effect of additional characters on choice of referring expression: Everyone counts. Journal of Memory and Language. 2007; 56(4):521-536. [DOI:10.1016/j. jml.2006.09.007] [PMID] [PMCID]

[28] Bard EG, Aylett, MP. Referential form, word duration, and modeling the listener in spoken dialogue. In: Trueswell JC, Tanenhaus, MK, editors. Approaches to Studying World-Situated Language use: Bridging the Language-as-Product and Language-as-Action Traditions. Cambridge: MIT Press; 2004.

[29] Chafe WL. Discourse, consciousness, and time. Chicago: Chicago University Press; 1994.

[30] Fukumura K, Van Gompel RPG, Pickering MJ. The use of visual context during the production of referring expressions. Quarterly Journal of Experimental Psychology. 2010; 63(9):1700-15. [DOI:10.1080/17470210903490969] [PMID]

[31] Karmiloff-Smith A. Language and cognitive processes from a developmental perspective. Informa UK Limited. 1985; 1(1):61-85. [DOI:10.1080/01690968508402071]

[32] Hickmann M, Hendriks H. Cohesion and anaphora in children's narratives: A comparison of English, French, German, and Mandarin Chinese. Journal of Child Language. 1999; 26(2):419-452. [DOI:10.1017/S0305000999003785] [PMID]

[33] Wong AMY, Johnston JR. The development of discourse referencing in Cantonese-speaking children. Journal of Child Language. 2004; 31(3):633-6. [DOI:10.1017/ S030500090400604X]

[34] Arnold JE. Reference production: Production-internal and addressee-oriented processes. Language and Cognitive Processes. 2008; 23(4):495-527. [DOI:10.1080/01690960801920099]

[35] American Psychiatric Association. Diagnostic and statistical manual of mental disorders ( $5^{\text {th }}$ edition). Washington, DC: American Psychiatric Association; 2013.

[36] Tager-Flusberg H. A psychological approach to understanding the social and language impairments of autism. International Review of Psychiatry. 1999; 11(4):325-34. [DOI:10.1080/09540269974203] [PMID] [PMCID]

[37] Losh M, Capps L. Narrative ability in high-functioning children with autism or Asperger's syndrome. Journal of Autism and Developmental Disorders. 2003; 33(3):239-51. [DOI:10.1023/A:1024446215446] [PMID]

[38] Novogrodsky R. Subject pronoun use by children with $\mathrm{Au}-$ tism Spectrum Disorders (ASD). Clinical Linguistics \& Phonetics. 2013; 27(2):85-93. [DOI: 10.3109/02699206] [DOI:10.31 09/02699206.2012.742567] [PMID]

[39] Banney RM, Harper Hill, K, Arnott WL. The Autism diagnostic observation schedule and narrative assessment: Evidence for specific narrative impairments in autism spectrum disorders. International Journal of Speech-Language Pathology. 2015; 17(2):159-71. [DOI:10.3109/17549507.2014.977348] [PMID]

[40] Tager Flusberg H, Paul R, Lord C. Language and communication in autism. In: Volkmar, FR, Klin, A, Cohen, DJ, editors. Handbook of Autism and Pervasive Developmental Disorders: Diagnosis, Development, Neurobiology, and Behavior. Hoboken, NJ: John Wiley and Sons, Inc; 2005.

[41] Taylor LJ, Whitehouse AJ. Autism spectrum disorder, language disorder, and social (pragmatic) communication disorder: overlaps, distinguishing features, and clinical implications. Australian Psychologist. 2016; 51(4):287-95. [DOI:10.1111/ap.12222]

[42] Fortea IB, Forner CB, Colomer C, Casas AM, Miranda BR. Communicative skills in Spanish children with Autism Spectrum Disorder and children with Attention Deficit Hyperactivity Disorder. Analysis through parents' perceptions and narrative production. Research in Autism Spectrum Disorders. 2018; 50:22-31. [DOI:10.1016/j.rasd.2018.02.006]

[43] Sah W, Torng P. Narrative coherence of Mandarin-speaking children with high-functioning autism spectrum disorder: An investigation into causal relations. First Language. 2015 35(3):189-212. [DOI:10.1177/0142723715584227]

[44] Tager-Flusberg H. Once upon a ribbit: Stories narrated by autistic children. British Journal of Developmental Psychology. 1995; 13(1):45-59. [DOI:10.1111/j.2044-835X.1995. tb00663.x]

[45] Tager-Flusberg H, Sullivan K. Attributing mental states to story characters: A comparison of narratives produced by autistic and mentally retarded individuals. Ap- 
plied Psycholinguistics. 1995; 16(3):241-56. [DOI:10.1017/ S0142716400007281] [DOI:10.1017/S0142716400007281]

[46] Vermeulen P. Context blindness in Autism Spectrum Disorder: Not using the forest to see the trees as trees. Focus on Autism and other developmental disabilities. 2015; 30(3):182-92. [DOI:10.1177/1088357614528799] [DOI:10.1177/1088357614528799]

[47] Baltaxe CAM. Pragmatic deficits in the language of autistic adolescents. Journal of Pediatric Psychology. 1977; 2(7):17680. [DOI:10.1093/jpepsy/2.4.176]

[48] Diehl JJ, Bennetto L, Young EC. Story recall and narrative coherence of high-functioning children with autism spectrum disorders. Journal of Abnormal Child Psychology. 2006; 34(1):83-98. [DOI:10.1007/s10802-005-9003-x] [PMID]

[49] Lindgren KA, Folstein SE, Tomblin JB, Tager Flusberg, $\mathrm{H}$. Language and reading abilities of children with autism spectrum disorders and specific language impairment and their first-degree relatives. Autism Research. 2009; 2(1):22-38. [DOI:10.1002/aur.63] [PMID] [PMCID]

[50] Gilliam JE. GARS-2: Gilliam autism rating scale. London: Pearson; 2005.

[51] Ahmadi SJ, Safari T, Hemmatian M, Khalili Z. [The psychometric properties of Gilliam Autism Rating Scale (GARS) (Persian)]. Research of Cognitive and Behavioral Sciences. 2011; 1(1):87-104.

[52] Yousefi N, Dadgar H, Mohammadi MR, Jalilevand N, Keyhani MR, Mehri A. [The validity and reliability of Autism Behavior Checklist in Iran (Persian)]. Iranian journal of Psychiatry. 2015; 10(3):144-9. [PMID] [PMCID]

[53] Kasechi M. [Validity and reliability of Persian version of Autism Spectrum Screening Questionnaire (Persian)] [MSc. Thesis]. Tehran: University of Social Welfare and Rehabilitation; 2011.

[54] Shahim S. Adaptation and standardization of wechsler Intelligence scale for children revised (WISC-R). Shiraz: University of Shiraz. $5^{\text {th }}$ edition; 2009 .

[55] Owens Jr RE. Language development: An introduction. London: Pearson; 2012.

[56] Mayer M. Frog, where are you? New York: Dial Press; 1969.

[57] Berman RA, Slobin DI. Relating events in narrative: A crosslinguistic developmental study. Hillsdale, NJ: Erlbaum; 1994.

[58] Serratrice L. Referential cohesion in the narratives of bilingual English-Italian children and monolingual peers. Journal of Pragmatics. 2007; 39(6):1058-87. [DOI:10.1016/j. pragma.2006.10.001]

[59] Botting N. Narrative as a clinical tool for the assessment of linguistic and pragmatic impairments. Child Language Teaching and Therapy. 2002; 18(1):1-22. [DOI:10.1191/0265659002ct224oa]

[60] Duinmeijer I, Jong JD, Scheper A. Narrative abilities, memory and attention in children with a specific language impairment. International Journal of Language and Communication Disorders. 2012; 47(5):542-55. [DOI:10.1111/j.14606984.2012.00164.x] [PMID]
[61] Reilly J, Losh M, Bellugi U, Wulfeck B. "Frog, where are you?" Narratives in children with specific language impairment, early focal brain injury, and Williams syndrome. Brain and Language. 2004; 88(2):229-47. [DOI:10.1016/S0093934X(03)00101-9]

[62] Fey ME, Catts HW, Proctor Williams K, Tomblin JB, Zhang $X$. Oral and written story composition skills of children with language impairment. Journal of Speech, Language, and Hearing Research. 2004; 47(6):1301-18. [DOI:10.1044/10924388(2004/098)]

[63] Hughes D, McGillivray L, Schmidek M. Guide to narrative language: Procedures for assessment. Menomonie: Eau Claire Wisconsin, Thinking; 1997.

[64] Justice LM, Bowles RP, Kaderavek JN, Ukrainetz TA, Eisenberg SL, Gillam RB. The index of narrative microstructure: A clinical tool for analyzing school-age children's narrative performances. American Journal of Speech-Language Pathology. 2006; 15(2):177-191. [DOI:10.1044/1058-0360(2006/017)]

[65] Bennetto L, Pennington BF, Rogers SJ. Intact and impaired memory functions in autism. Child Development. 1996; 67(4):1816-35. [DOI:10.2307/1131734] [PMID]

[66] Joseph RM, Steele SD, Meyer E, Tager-Flusberg H. Selfordered pointing in children with autism: Failure to use verbal mediation in the service of working memory? Neuropsychologia. 2005; 43(10):1400-11. [DOI:10.1016/j.neuropsycholoe gia.2005.01.010] [PMID] 
Appendix A. The variables' definitions and examples

\begin{tabular}{|c|c|c|}
\hline Items & Description & Example(s) \\
\hline 1. Full noun phrase & A phrase that consists of a noun as a head. & $\begin{array}{l}\text { pesær kutfulu } \\
\text { 'the little boy' }\end{array}$ \\
\hline $\begin{array}{l}\text { 2. Independent } \\
\text { pronoun }\end{array}$ & $\begin{array}{l}\text { Words that can be substituted for nouns or noun phrases, and they } \\
\text { can stand by themselves (e.g. personal: mæn 'I', to 'you', u: 'he/ } \\
\text { she', ma 'we', Joma 'you', ?anha 'they', demonstrative: ?in 'this', ?an } \\
\text { 'that'). }\end{array}$ & $\begin{array}{l}\text { Pin færar kærd. } \\
\text { 'this escaped.' }\end{array}$ \\
\hline $\begin{array}{l}\text { 3. Dependent pro- } \\
\text { noun }\end{array}$ & 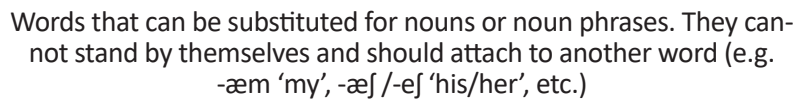 & $\begin{array}{l}\text { sær-e } \\
\text { 'his head' }\end{array}$ \\
\hline 4. Complete ellipsis & $\begin{array}{l}\text { When there is no overt representation for a reference, the refer- } \\
\text { ence is implicit. }\end{array}$ & $\begin{array}{l}\varnothing \text { ræft ruje deræxt. } \\
\text { ‘ (he) climbed up the tree.' }\end{array}$ \\
\hline $\begin{array}{l}\text { 5. Inflection of the } \\
\text { verb }\end{array}$ & $\begin{array}{l}\text { Verbs can be inflected by -æm ' } 1 s g^{\prime},-i \text { ' } 2 s g^{\prime} \text {, -æd ' } 3 s g^{\prime},-i m \text { ' } 1 p l \text { ', -id } \\
\text { ' } 2 \mathrm{pl} \text { ', -ænd ' } 3 p \mathrm{pl}^{\prime} \text { which indicate person and number of the subject } \\
\text { on the verb. }\end{array}$ & $\begin{array}{l}\text { pesær qurbaqæ ro pejda kærd. } \\
\text { 'The boy found the frog.' }\end{array}$ \\
\hline
\end{tabular}

Appendix B. The examples of reference introduction

Introduction

Noun phrase

Dependent pronoun

Boy

Independent pronoun

Complete ellipsis

Inflection of verb

Noun phrase

Dependent pronoun

Dog

Independent pronoun

Complete ellipsis

Inflection of verb

Noun phrase

Dependent pronoun

Frog

Independent pronoun

Complete ellipsis

Inflection of verb pesær je qurbaqe daft ba je sæg.

'The boy had a frog with a dog'.

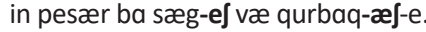
'The boy is with his frog and his dog'

$\varnothing$ xabid.

‘ $\varnothing$ (The boy) slept'.

pesær qurbaqæro negah mikone. 'The boy is watching the frog'.

je ruz, je qurbaqe bud. 'One day, there was a frog'.

in dare negah mikone.

'This is watching'.

$$
\varnothing \text { oftad }
$$

' $\varnothing$ (the dog) fell'.

sæg ham dare negah mikone. 'The dog was watching, too'.

je qurbaqe tuje fifæst.

'A frog is in the jar'.

indza $\varnothing$ dare seda mizæne. 'Here, $\varnothing$ (the boy) is calling it'.

$\emptyset$ dare mijad birun

' $\varnothing$ (The frog) is going out'.

$\varnothing$ dare mijad birun. ' $\varnothing$ (The frog) is going out'. 
Appendix C. The examples of reference reintroduction

\begin{tabular}{|c|c|c|}
\hline & & oduction \\
\hline \multirow{5}{*}{ Boy } & Noun phrase & $\begin{array}{l}\text { in gavazn indzast, bæ:d in pesær oftad. } \\
\text { 'This deer is here, then the boy fell'. }\end{array}$ \\
\hline & Dependent pronoun & $\begin{array}{l}\text { qurbaqæjæm mijad birun. } \\
\text { 'His frog went out'. }\end{array}$ \\
\hline & Independent pronoun & $\begin{array}{l}\text { un fekr kard ke } \varnothing \text { ræfte. } \\
\text { 'He thought that } \varnothing \text { (it) has gone'. }\end{array}$ \\
\hline & Complete ellipsis & $\begin{array}{l}\text { qurbaqe færar kærd, bæ: } \varnothing \emptyset \text { bidar Jod. } \\
\text { 'The frog escaped, then } \emptyset \text { (the boy) woke up'. }\end{array}$ \\
\hline & Inflection of verb & $\begin{array}{l}\text { sæg oftad, bæ: } \varnothing \text { goft qurbaqe kodzaji? } \\
\text { 'The dog fell, then } \varnothing \text { (he) said where are you?' }\end{array}$ \\
\hline \multirow{5}{*}{ Dog } & Noun phrase & $\begin{array}{l}\text { pesær æz pændzere negah kærd, væ sag oftad. } \\
\text { 'The boy looked out of window, and the dog fell'. }\end{array}$ \\
\hline & Dependent pronoun & $\begin{array}{l}\text { pesær donbale qurbaqe migæft, sære tuje fije gir kærd. } \\
\text { 'The boy was searching for the frog, its head stuck in the jar'. }\end{array}$ \\
\hline & Independent pronoun & $\begin{array}{l}\text { pesær oftad pajin, inam dare færar mikone. } \\
\text { 'The boy fell down, this was escaping, too'. }\end{array}$ \\
\hline & Complete ellipsis & $\begin{array}{l}\text { pesær qurbaqæro seda zæd, bæ: } \varnothing \varnothing \text { ba jife oftad. } \\
\text { 'The boy called the frog, then } \emptyset \text { (the dog) fell with the jar'. }\end{array}$ \\
\hline & Inflection of verb & $\begin{array}{l}\text { pesær oftad, sæg hæm oftad. } \\
\text { 'The boy fell, the dog fell, too. }\end{array}$ \\
\hline \multirow{5}{*}{ Frog } & Noun phrase & $\begin{array}{l}\text { pesær goft qurbaqe ræfte. } \\
\text { 'The boy said the frog has escaped'. }\end{array}$ \\
\hline & Dependent pronoun & $\begin{array}{l}\text { pesær hæmeja-ro donbalef gæet. } \\
\text { ‘The boy searched everywhere for it. }\end{array}$ \\
\hline & Independent pronoun & $\begin{array}{l}\text { Pesær pofte tfubo negah kærd, un undza bud. } \\
\text { 'The boy looked over the log, it was there. }\end{array}$ \\
\hline & Complete ellipsis & $\begin{array}{l}\text { pesær fekr kærd, } \varnothing \text { ræfte. } \\
\text { 'The boy thought, } \emptyset \text { (the frog) has gone. }\end{array}$ \\
\hline & Inflection of verb & $\begin{array}{l}\text { pesær porsid, qurbaqe undzast? } \\
\text { 'The boy asked, is the frog there? }\end{array}$ \\
\hline
\end{tabular}

Appendix D. The examples of reference maintenance

\section{Maintenance}

Noun phrase

Dependent pronoun

Boy

Independent pronoun

Complete ellipsis

Inflection of verb

Noun phrase

Dependent pronoun

Dog

Independent pronoun

Complete ellipsis

Inflection of verb pesær dad zæd, pesær donbale qurbaqe gæ]t

'The boy called, the boy searched for the frog'.

pesær migæ $\int t, \varnothing$ tuje tæækmehaje bozorge ro negah mikærd. 'The boy was searching, $\varnothing$ (the boy) was looking in his big boots.

pesær ruje gævæzn bud, bæ:d in oftad tu a:b.

'The boy was on the deer, then he fell into the water'.

pesær oftad tu a:b, bæ:d $\emptyset$ goft saket baf.

'The boy fell into the water, then $\emptyset$ (he) said be quiet'.

pesær tærsid, bæ:d $\varnothing$ oftad tu a:b.

'The boy scared, then $\varnothing$ (he) fell into the water'.

sæg oftad. bæ:d sæg lise zæd.

'The dog fell. Then, the dog licked him.

sæg oftad pajin. dæste $\int$ dærd gereft.

'The dog fell down. Its hand ached.

sæg tærsid. In dare færar mikone.

'The dog scared. This was escaping'.

sæg oftad. $\varnothing$ lise $\int$ mizæne.

'The dog fell. $\varnothing$ (the dog) is licking him.

sæg tærsid. $\varnothing$ færar kærd.

'The dog scared. $\varnothing$ (the dog) escaped. 


\begin{tabular}{|c|c|c|}
\hline & \multicolumn{2}{|c|}{ Maintenance } \\
\hline & Noun phrase & $\begin{array}{l}\text { qurbaqe indza bud. qurbaqe xofhal fod. } \\
\text { 'The frog was there. The frog became happy'. }\end{array}$ \\
\hline & Dependent pronoun & $\begin{array}{l}\text { qurbaqe indza nejæste. je pa birune. } \\
\text { 'The frog sat here. One of its leg is out'. }\end{array}$ \\
\hline \multirow[t]{3}{*}{ Frog } & Independent pronoun & - \\
\hline & Complete ellipsis & $\begin{array}{l}\text { qurbaqe indza nist. } \varnothing \text { indza ham nist. } \\
\text { 'The frog is not here. } \varnothing(\mathrm{It}) \text { is not here, too'. }\end{array}$ \\
\hline & Inflection of verb & $\begin{array}{l}\text { qurbaqe ke færar kærde bud, } \varnothing \text { pife xanevadæe bud. } \\
\text { 'The frog that had escaped, (it) was with his family'. }\end{array}$ \\
\hline
\end{tabular}


